\title{
You can run, but you can't hide: Good technique but imperfect science
}

\author{
Christina L. Greene, MD, ${ }^{\mathrm{a}}$ and P. Michael McFadden, $\mathrm{MD}^{\mathrm{b}}$
}

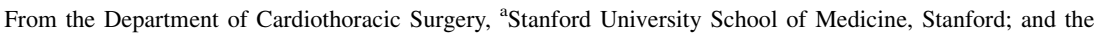
${ }^{\mathrm{b}}$ Keck School of Medicine, University of Southern California, Los Angeles, Calif. Disclosures: Authors have nothing to disclose with regard to commercial support.

Received for publication Dec 20, 2016; accepted for publication Dec 27, 2016; available ahead of print Feb 6, 2017.

Address for reprints: P. Michael McFadden, MD, Department of Cardiothoracic Surgery, Keck School of Medicine, University of Southern California, 1520 San Pablo St, Suite 4300, Los Angeles, CA 90033 (E-mail: Michael.McFadden@med.usc.edu).

J Thorac Cardiovasc Surg 2017; 153:1189-90

$0022-5223 / \$ 36.00$

Copyright (c) 2017 by The American Association for Thoracic Surgery

http://dx.doi.org/10.1016/j.jtcvs.2016.12.027
}

Advancements in surgical technique are hard to validate. Subtle adjustments to surgical technique can have large unanticipated consequences that are often not appreciated until much later. Compounding this difficulty are rare pathologies that may not be seen on a frequent enough basis to study. This conundrum leaves the scientific community to interpret the success of a new technique on the basis of piecemeal retrospective data. Thus it is left to our surgical judgment to determine whether it is reasonable to

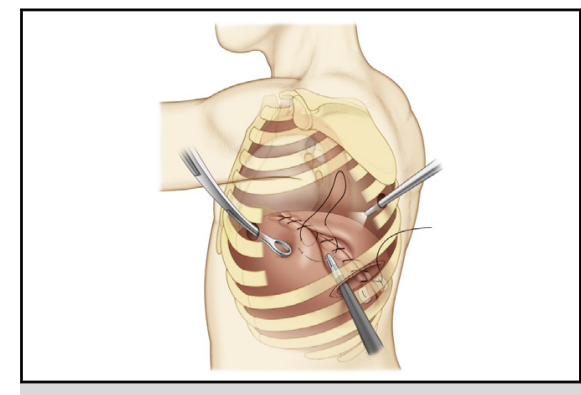

This excellent illustration from the article clearly shows how the technique is performed.

\section{Central Message}

Surgical advancements are often underappreciated at their inception, and it may be years before their impact is felt. The running technique described here will likely be one of those techniques.

See Article page 1182 .

See Editorial page 1180 .

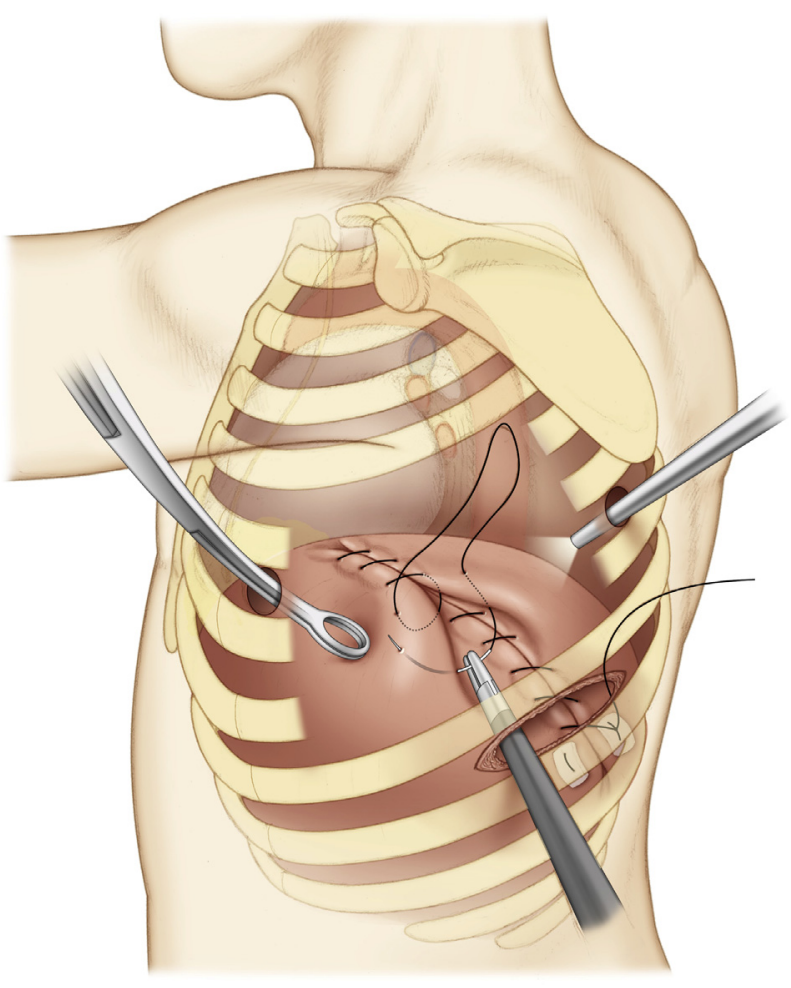

FIGURE 1. This excellent illustration from the article of Demos and colleagues ${ }^{1}$ clearly shows how the technique is performed. adopt a new procedure until prospective studies can be performed.

In this issue of the Journal, Demos and colleagues ${ }^{1}$ present a novel technique for minimally invasive diaphragm plication in their article, "Video-Assisted Thoracoscopic Diaphragm Plication Using a Running-Suture Technique is Durable and Effective." This article describes a minimally invasive technique in which a running horizontal mattress suture is used in a to-and-fro motion to plicate the diaphragm. The self-retaining nature of this technique allows the surgeon to maintain constant tension on the diaphragm. This contrasts with previous attempts at minimally invasive plication, which require multiple interrupted stitches and thus obligate the surgeon to perform multiple intrathoracic knots at difficult angles. ${ }^{2}$ The awkwardness and technical difficulty of the interrupted technique is likely responsible for its lack of appeal.

Although the running suture technique itself is reasonable, this study suffers from the same problems as many articles on surgical technique. First, it is simply statistically underpowered. ${ }^{3,4}$ There were 18 patients in this study, with complete data for only 14 . Second, it is a purely retrospective study without a control group, eliminating the ability to make comparisons with the current 
interrupted-plication technique. Third, the median followup was only 29 months, making it difficult to conclude the long-term durability of this repair. Finally, the measures used for evaluation were acquired in a retrospective fashion, with patients asked at the time of the study to recall their symptoms before and 6 months after the operation. This method of obtaining data is not ideal and carries inherent recall bias. Pulmonary function tests, which would allow unbiased quantitation of improved lung function, were only acquired at a median of 6 months after the operation.

That being said, we should not lose sight of the forest for the trees. Although the scientific evaluation of this study is flawed, the surgery is appealing. This technique is nicely illustrated (Figure 1) and demonstrated in the accompanying video. It could easily be adapted by those with moderate thoracoscopic skill. At 6 months, the plication did show a statistically significant improvement in forced expiratory volume in 1 second and forced vital capacity, demonstrating its efficacy, and the symptomatic benefit of the plication was stable at 29 months, demonstrating its shortterm durability.
Surgeons are constantly searching for ways to make their operations safer, faster, and more effective. This leads to intraoperative innovation and advancements. These advancements are often underappreciated at their inception, and their impact is often not felt for many years. This running suture technique is one such advancement.

Although the scientific evaluation is imperfect, the method of diaphragm plication put forward by Demos and colleagues ${ }^{1}$ is minimally invasive, noncomplex, and faster. It could well become the new standard, provided its longterm durability can be proved.

\section{References}

1. Demos DS, Berry MF, Backhus LM, Shrager JB. Video-assisted thoracoscopic diaphragm plication using a running suture technique is durable and effective. $J$ Thorac Cardiovasc Surg. 2017;153:1182-8.

2. Freeman RK, Van Woerkom J, Vyverberg A, Ascioti AJ. Long-term follow-up of the functional and physiologic results of diaphragm plication in adults with unilateral diaphragm paralysis. Ann Thorac Surg. 2009;88:1112-7.

3. Maggard MA, O’Connell JB, Liu JH, Etzioni DA, Ko CY. Sample size calculations in surgery: are they done correctly? Surgery. 2003;134:275-9.

4. Cadeddu M, Farrokhyart F, Achilleas T, Haines T, Garnett A, Goldsmith CH. Evidence-Based Surgery Working Group. Users' guide to the surgical literature: how to assess power and sample size. Laparoscopic vs open appendectomy. Can J Surg. 2008;51:476-82. 